\title{
Psychogenic Seizure
}

National Cancer Institute

\section{Source}

National Cancer Institute. Psychogenic Seizure. NCI Thesaurus. Code C116548.

Movements, behaviors and sensations similar to a seizure, but due to psychological

distress instead of a neurological disorder. 